\title{
LA ARTIMAÑA DE PENÉLOPE. UNA MIRADA DE GÉNERO Y TRANSNACIONAL A LA MIGRACIÓN ITALIANA DE FINALES DEL SIGLO XIX Y PRINCIPIOS DEL XX A TRAVÉS DE LA FOTOGRAFÍA DE FAMILIA
}

\author{
PENELOPE'S RUSE. A GENDER AND TRANSNATIONAL LOOK \\ AT THE ITALIAN MIGRATION OF THE LATE NINETEENTH AND EARLY \\ TWENTIETH CENTURY THROUGH FAMILY PHOTOGRAPHY \\ CAROLINA BUITRAGO ECHEVERRY* \\ LAURA MELISSA ACEVEDO FRANCO** \\ SHARIK STEFANNY GUZMÁN MERA*** \\ PAOLA ORTIZ RÍOS****
}

\begin{abstract}
RESUMEN
Se aborda la fotografía de familia de final del siglo XIX y principios del XX como un escenario complejo donde se redefinen y negocian identidades transnacionales en el marco de la migración italiana de dicha época. Nos centramos especialmente en el papel de la mujer a la hora de regular esos flujos simbólicos. Mediante una mirada etnográfica multisituada, nos adentramos en las estrategias y artimañas con la que las mujeres distribuían el capital simbólico, que se reflejaban en la fotografía. Hallamos que, a pesar del contexto de moralidad en la que estaban encalladas, lograban ejercer un poder simbólico muy sofisticado. Concluimos que ese poder se colaba en los sistemas de metaforización que regulaban las relaciones sociales $y$, que, a diferencia del ejercido por el hombre, no se definía en contraposición a ningún sistema; todo lo contrario, su influencia no necesita de legitimación: son actos a la vez privados y públicos, subjetivos e intersubjetivos; es decir, tienen un carácter multisituado.
\end{abstract}

PALABRAS CLAVE: migración transnacional, etnografía multisituada, dispositivo simbólico, performatividad, rol, poder.

\begin{abstract}
We approach family photography at the end of the 19th century and the beginning of the 20th century as a complex scenario where transnational identities are redefined and negotiated within the framework of the Italian migration of that era. We focus especially on the role of women in regulating these symbolic flows. Through a multi-sited ethnographic perspective, we delve into the strategies and tricks with which women distributed symbolic capital, which was reflected in photography. We find that, despite the context of morality in which they were stuck, they managed to exert a very sophisticated symbolic power. We conclude that this power slipped into the systems of metaphorization that regulated social relations and that, unlike that exercised by man, was not defined in opposition to any system; on the contrary, their influence does not need legitimization: they are both private and public, subjective and intersubjective acts; that is, they have a multiset character.
\end{abstract}

KEYWORDS: transnational migration, multisite ethnography, symbolic device, performativity, role, power.

* Joven investigadora de Colciencias. Comunicadora Social. Facultad de Ciencias Humanas Sociales y de la Educación. Universidad Católica de Pereira.

carolina.buitrago@ucp.edu.co

** Comunicadora Social. Facultad de Ciencias Humanas Sociales y de la Educación. Universidad Católica de Pereira.

laura.acevedo@ucp.edu.co

*** Comunicadora Social. Facultad de Ciencias Humanas Sociales y de la Educación. Universidad Católica de Pereira. sharick.guzman@ucp.edu.co

**** Comunicadora Social. Facultad de Ciencias Humanas Sociales y de la Educación. Universidad Católica de Pereira.

paola.ortiz@ucp.edu.co 
A la memoria de Yannick Geffroy y Patrick Accolla, que abrieron la caja de galletas de hojalata que contenía miles de historias sorprendentes $y$ fotografias.

\section{INTRODUCCIÓN}

Este artículo rescata algunas conclusiones de un estudio etnográfico que se realizó en la región de la Toscana (Italia), entre los años 2004 y 2005, y cuyos resultados fueron publicados por la Revista Española de Investigaciones Sociológicas (REIS) en el 2014, bajo el nombre de "Tensiones sociales en la representación fotográfica del periodo 1870-1930" (Romero Tenorio, 2014). En esta ocasión, queremos profundizar en algunos trechos que se abismaban en el papel de la mujer en la emigración italiana de ese período, sobre todo hacia el continente americano, y más particularmente a Argentina, Uruguay, Chile, Perú y Estados Unidos, coincidiendo con el desarrollo económico de esos países, que se vieron atravesados por un sistema avanzado de redes ferroviarias y viales que las manos de los italianos contribuyeron a trazar.

Habiendo sido las ofertas de trabajo principalmente físicas, de construcción, la mayoría de esa migración fue, en una primera fase, masculina. Es interesante anotar, y eso se ve reflejado en tantas cartas y postales que pudimos recopilar, cómo estos migrantes tenían intención de retornar a Italia (Taborda y Riccardi,
2019); sin embargo, tres circunstancias hicieron que echasen raíces en los países de destino y terminaran llevando a sus familias. Para comenzar, la creación de sólidas redes solidarias (Díez Jiménez y Cabrera Izquierdo, 2010), que se manifiesta, por ejemplo, en la constitución de instituciones asistenciales propias, por la tradición sindical italiana. Así, en muchas ciudades argentinas, existían hospitales y escuelas italianas fundadas $\mathrm{y}$ financiadas por los propios trabajadores italianos. En segundo lugar, la migración italiana fue especialmente emprendedora en el lugar de destino. Para terminar, la Primera Guerra Mundial creó un escenario de caos a un lado y al otro de los Apeninos, poco atractivo para la vuelta de estos migrantes.

Las esposas de estos jóvenes migrantes se tropezaron con una extraña condición: no se desplazaron a otro país y, sin embargo, fueron relegadas a un rol liminal. No estaban ni allí ni acá (Bossio Blanco, 2019). Se vieron obligadas, en definitiva, a cargar con el peso de mantener vivos, simbólicamente, los vínculos familiares, escenificando la unión por una serie de actos: ir a la Iglesia; al mercado; el recato, en forma de vestidos negros; asistían a las fiestas del pueblo en riguroso segundo plano, etc., actitudes, en definitiva, que se amoldan a la horma de la moralidad de esa época. No solo se encontraban solas; tenían, asimismo, que escenificar esa soledad ante los ojos de ellas mismas y de la sociedad. 
Entre esos dispositivos simbólicos (Romero Tenorio, Buitrago Echeverry y Echeverry Blanco, 2017) que estas mujeres usaban para urdir esta compleja trama encontramos a la fotografía de familia, que jugó un rol de catalizador de las emociones subjetivas e intersubjetivas. El trabajo de Romero Tenorio (2014) va por los derroteros de una microetnografía en la que reconstruye el contexto de esas fotografías por medio de entrevistas y relatos de vida. A partir de ese material, erigimos a la fotografía de familia como "ritual trasnacional” (Gardner y Grillo, 2002). Estos autores invitaban a analizar el fenómeno de las migraciones trasnacionales más allá de los flujos físicos (el movimiento de personas) o económicos (el tránsito de capitales), atendiendo también a las reconfiguraciones que se producen, al interior de las familias, a raíz de estos movimientos migratorios trasnacionales (Fouskas Gikopoulou, Ioannidi y Koulierakis, 2019).

La fotografía de familia del período delimitado por la investigación tiene unos componentes globales absolutamente fascinantes. De igual manera que hoy en día los patrones estéticos de las selfies se repiten en todos los rincones del mundo, en los comienzos de su popularización, a uno y a otro lado del océano, la representación fotográfica responde a los mismos esquemas. Las imágenes recogidas en Italia por Romero Tenorio son similares a las recopiladas por Accolla y Geffroy (1981) en su trabajo de reconstrucción histórica de la época en la Costa Azul francesa; todos esos clichés, con los mismos códigos, aparecen colgados en una exposición que apenas vimos en el Conservatorio Pedro Morales Pino de Cartago (Colombia). ¿Cómo es posible que las prácticas sean las mismas cuando en aquella época las vías de globalización eran escasas?

Dicha epistemología describe los modos de repartición del capital simbólico a lo largo de las diferentes etapas del proceso migratorio (Riccardi y Agudelo Taborda, 2015). Por ejemplo, en un interesante estudio sobre los ritos escenificados por las familias marroquíes emigradas a Italia durante su retorno vacacional (normalmente en verano) a su país natal, Rubah Salih describe la distribución del capital simbólico en los diferentes espacios trasnacionales. Su visión es pertinente para nuestra investigación en cuanto tiene en cuenta "la dimensión transnacional de los rituales y las ceremonias" (Salih, 2002, p.219). Lo que propone en definitiva Salih es desanclar los procesos rituales de los contextos en los que se producen, ampliando la visión de tal manera que lo que se termina escrutando es "la intersección entre las interconexiones globales y locales" (Salih, 2002, p.219), y no el rito en sí. La forma multisituada de producir el territorio de estos actores hace que "su vida sea optimizada" (Salih, 2002, p.221), en cuanto aprovechan su vuelta para hacerse arreglos en la boca 
o tratamientos capilares profundos, ya que la vida en Italia es mucho más cara que en Marruecos. Por no hablar de la compra de una vivienda. En este caso concreto, la escrituración de un bien no describe la circulación de flujos monetarios del centro a la periferia; constituyen, más bien, un solapamiento simbólico de ambos escenarios donde las prácticas adquieren una dimensión ritual, en el sentido en el que lo describe Marcel Mauss con su concepto de Potlach. Este desgrana la lógica don/contradon, es decir, la multidireccionalidad de los ritos. Los migrantes marroquíes, a través de estas acciones, "negocian sus identidades vis-à-vis con los que se quedan en casa" (Salih, 2002, p.221). Aparte de la integración en el retorno (Díez Jiménez, 2010) y el reforzamiento de su identidad, ostentan "un nuevo estatus social y, por esta vía, la modernidad” (Salih, 2002, p.228).

Las bodas que organizan son fastuosas y se mezclan elementos heterogéneos: por ejemplo, la solemnidad de la tradición de la unión marital en la cultura musulmana está revuelta con elementos provenientes de una modernidad occidental, como la costumbre de llegar en un coche de lujo, los banquetes a la italiana, con siete platos y canapés interminables.

En el marco de la migración colombiana (Díez Jiménez, 2015) en París, observamos las mismas dinámicas. Resaltar que la mayor parte de esta colonia proviene de dos pueblos: Cartago (Valle del Cauca) y Santuario (Risaralda). Estos migrantes, por el alto coste de la vida francesa, habitan, generalmente, de alquiler en los banlieux del cinturón que rodea a la capital francesa. A sus parientes y conocidos que se quedan en el país cafetero, ellos les transmiten que viven en París, no solo por una cuestión de facilitar la ubicación (nadie en Colombia conoce Bondy, por ejemplo); sino sobre todo por el estatus simbólico que otorga el empadronarse en la ciudad de la luz. Incluso, las fotografías que comparten en las redes sociales, rara vez escenifican estos pueblos de la periferia: lo hacen mostrando los lugares emblemáticos de París.

Otra investigación sobresaliente sobre los rituales transnacionales sigue el proceso de repatriación de los difuntos senegaleses que fallecen en Cataluña y son trasladados a Senegal, realizada por Solé Arrarás (2017). La naturaleza multisituada de este trabajo exigió, a la autora, investigar en contextos múltiples y analizar cómo el ritual transnacional configuraba el objeto o el sujeto. El estatus cambiante del cadáver (a veces tienen un signo humano, otras veces es un troquel con el cual negociar significados simbólicos) oscila por su inserción en las diversas esferas simbólicas. El ritual no se define como un hecho, sino como un proceso en el que los intercambios simbólicos y las transferencias modifican su naturaleza. Tal es así que, para esta antropóloga, 
la construcción de rituales que se producen a la vez en el país de instalación y en el de origen nos habla de la generación de identidades de carácter transnacional, por lo que los traslados de cadáveres producen nuevos lugares, nuevos escenarios de pertenencia. (p.105)

Es el ritual el que configura una comunidad transnacional, cuyas prácticas varían según la situación y la relación entre los miembros, estando reguladas por el reparto de los capitales simbólicos.

Es a partir de estas perspectivas multisituadas que nos proponemos acercarnos a las prácticas rituales trasnacionales en el seno de las familias en la comarca de la Lunigiana de la Toscana (Italia), en el período de finales del siglo XIX y principios del XX, por medio de los testimonios fotográficos y etnográficos.

\section{METODOLOGÍA}

La perspectiva transnacional nos lleva a entender los procesos migratorios más allá de los desplazamientos de las personas (Salvatori y Terrón, 2019), haciendo hincapié en los transfers simbólicos desde una visión multisituada. Para Marcus (1998), una etnografía de tal naturaleza, se mueve fuera de los lugares únicos y las situaciones locales de los diseños convencionales de investigación etnográfica para examinar la circulación de significados cultu- rales, objetos e identidades en un espacio y tiempo difusos. (Marcus, 1998, p.79)

Para este autor, los fenómenos que atraviesan diferentes escenarios y temporalidades (Romero Tenorio, 2017) son tan complejos que la etnografía debería, en primer lugar, captar esta multiplicidad (Marcus, 1998, p.52).

Esta se nos presenta en forma de collage a la hora de "seguir el fenómeno", como impostaba Marcus. Como el objeto de estudio no es monolítico y se resuelve en diferentes intensidades, toca aprehenderlo desde los fragmentos y nuestra labor etnográfica se ciñe a reconstruir historias a medias. Para Marcus este rasgo no es problemático "en cuanto es fundamental ordenar y probar la relación entre materiales dispersos” (Marcus, 2001, p.114). Con este fin "el etnógrafo se vuelve móvil” (Marcus, 2001, p.114) en la medida en que el relato etnográfico urde, en una trama, una heterogeneidad de retazos. Esta de-forma de hacer etnografía entra en conflicto con otras praxis, como la textual de Clifford Geertz (2003), que con su "descripción densa" seguía las tramas de significación de los fenómenos, capa a capa, hasta su enraizamiento en un contexto espacio-temporal bien determinado (Romero Tenorio, 2014).

Estando enfrentadas a una realidad organizada en episodios, se nos dificultó establecer una unidad de análisis bien de- 
finida. Fotografías de finales del siglo XIX y principios del XX, testimonios de los parientes actuales de los que aparecían en esas fotografías y cartas postales constituían nuestro corpus. A diferencia del método histórico, que pretende darle una unidad temporal, para nosotras prevaleció la démarche fragmentaire; esto es, no pusimos nuestro énfasis en la coherencia, en cuestionar lo infundado de las fuentes, en restablecer la línea temporal. Se esgrimía, más bien, las intensidades, el pálpito de las fotografías, las discordancias de los testimonios y que, a partir de todo ello, el lector sentipensara (Vega Casanova, 2016) con los protagonistas de las fotografías. No le queremos ofrecer un panorama monolítico, sino alveolos por los que expirar e inspirar el mismo oxígeno que esos personajes acartonados.

Se recogieron más de trecientas fotografías que componían la memoria visual de una pequeña región de la Toscana, la Lunigiana, entre 2004 y 2005, que se contextualizaron por medio de entrevistas e historias de vida, a los descendientes de los actores que figuraban en dichos clichés, que sirven de material a esta investigación.

Previa organización de la información, procedimos a indexarla por categorías, a partir de las cuales identificamos cuatro patrones recurrentes que transformamos en temas de análisis: Performatividad hedonista, intrascendencia, dispositivo simbólico y negociación de roles.
El proceso de entendimiento de la información previamente indexada pasa por la perspectiva trasnacional, según la cual existe una distribución del "capital simbólico” (Bourdieu, 1979, p.242) entre todos los actores que conforman las trayectorias vitales de la migración (Campani, 2019). Se escrutaron, tras la fotografía, las lógicas de ese reparto en el que entra en juego la negociación de identidades, la asignación de roles y el mantenimiento de imaginarios.

\section{ANÁLISIS DE DATOS}

\section{1. ¿Una época oscura para las mujeres?}

No podemos obviar que las etnógrafas que nos enfrentamos con este ingente material quisimos, de alguna manera, completar esos huecos del collage con nuestras propias ideologías. Nos resultaba muy fácil recurrir al rol subalterno de las mujeres para re-victimizarlas (Monreal Gimeno, Cárdenas Rodríguez y Martínez Ferrer, 2019), considerándolas simples peleles de un sistema religioso y social. Sin embargo, fotografías como la de la siguiente página hacía temblar nuestros prejuicios.

Si la mujer tuviera un rol tan preestablecido en esa sociedad, ¿cómo es posible que una fotografía de los años 20 como tal pudiese ser tomada y hubiese llegado a nuestros días? 
Figura 1. Performatividad de género

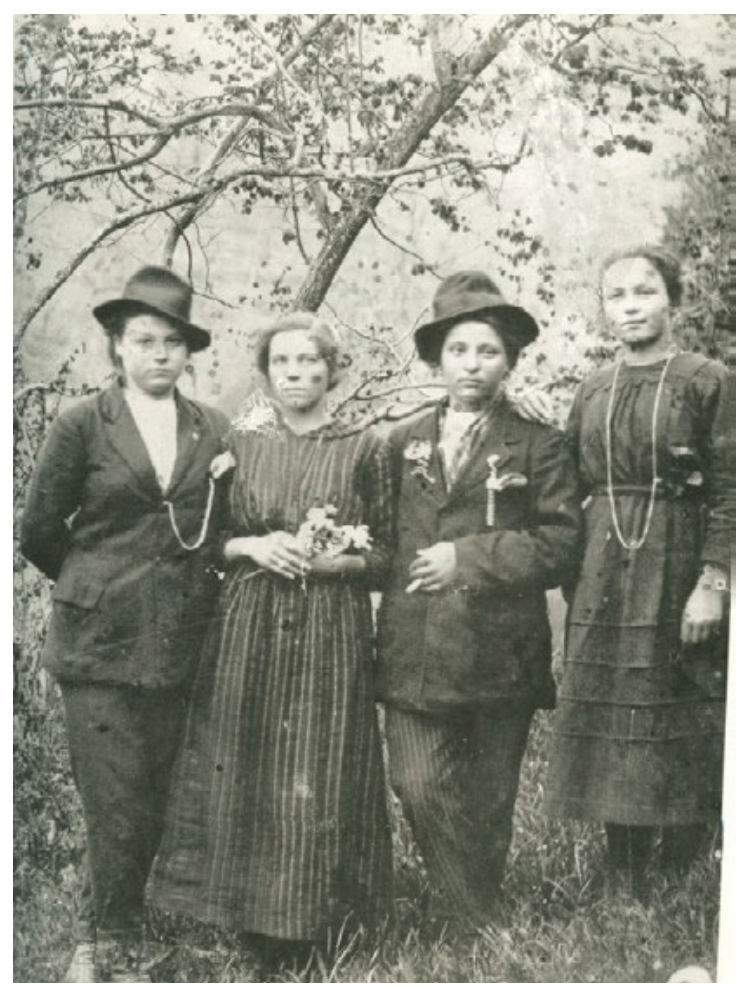

Fuente: Alrededor de 1920, archivo de la investigación.

Romero Tenorio, que recolectó esta imagen, nos relata que expuso este trabajo en muchos escenarios, tanto universitarios como culturales. Cuando presentaba esta fotografía, siempre había en el público alguna feminista que consideraba esta fotografía un acto de liberación sexual, a modo de la performatividad de Agnès que relató Garfinkel (1968). Era una transexual que aprendió a usar rutinariamente las prácticas comunes por las cuales, llegaba a ser, en sentido sociológico, una mujer.

Esos intervinientes veían el hecho etnográfico por medio de una ideología que impedía que la sístole y la diástole de la fotografía bombeara la sangre. El hecho de que unas mujeres se vistieran de hombre en los años 20 del siglo pasado no tiene que ser debido a una reivindicación sexual. Situar a la mujer en continuo estado de eyección, de defensa en contra de un hetero-patriarcado (Binazzi, 2019) evita que ejerzan una serie de poderes perturbadores para el sistema: la intrascendencia y el hedonismo. ¿Por qué todo lo que hace la mujer tiene que servir para algo? Como Pierre Bourdieu señaló en su obra La Distinción (1979), las clases que dominan lo hacen precisamente por su carácter antipragmático, por disfrutar de las cosas sin interés práctico alguno. Y muchas de estas manifestaciones culturales intrascendentes pertenecen a su consumo cultural. Así Janice Radway (1984) demostró que tras esta nimiedad se esconde una red de poder que cambia el sentido de la dominación (Romero Tenorio y Díaz 2014, p.70). Su etnografía en una librería londinense especializada en novela rosa la describe como un espacio de contestación que determina el sistema de producción de esas novelas. Es el concurso activo de las lectoras de relatos románticos quien mantiene en vida los intercambios simbólicos. Ellas imponen cómo tiene que ser la tipografía, la foto de portada, la estructura del relato. Si no se acomoda a estos preceptos, la novela simplemente no trasciende. Dot, la librera, creó una suerte de catálogo, Dorothy's diary of romance reading. Las clientes, con su intercambio de impresiones acerca de las novelas, las prescriben, y las 
casas editoras cuidan en satisfacer las exigencias del público. Radway, amargamente, concluye que "estas pequeñas victorias" que se generaron desde la cultura viviente del consumo de esta novela,

logradas en el difícil terreno del ocio son difícilmente traspasables a otras esferas y, sobre todo, no constituyen el fundamento de una contestación más amplia contra el orden social dominante (Radway, 1988, p.370)

La lectura fragmentaria de los productos culturales de la mujer revela también una intrascendencia en la que se ejerce una cierta forma de poder (Romero Tenorio, Zuluaga Morales, García Hernández, 2016). Por ejemplo, Vogue o Elle se articulan en la desarticulación de contenidos: en una misma página se encuentra una serie de materiales heterogéneos que propicia que sea la mujer la que elija el recorrido de lectura: puede comenzar de la página que quiera, va de un contenido hacia otro con naturalidad: consejos, crónicas, consultorio amoroso, imágenes, publicidad. Para Benjamin (2005) esta forma de consumir rompe la unicidad del relato y, por tanto, su espejismo totalizante, base de la sacralización de la sociedad. La mano y el ojo va, cada uno, por un lado, rompiendo el efecto mágico de la coordinación ojo-mano-alma, propio del arte oficial que veía, en una especie de trascendencia, la salvación de la banalidad. Cuando una mujer lee una revista de corazón, opera como el cirujano frente al mago, según una metáfora diciente del filósofo alemán: "el mago mantiene la distancia entre él mismo y el paciente (...) la reduce un poco gracias al toque de su mano y la incrementa mucho gracias a su autoridad” (Benjamin, 2003, p.80). A su eficacia simbólica, diría Lévi-Strauss. Por el contrario, el cirujano procede a la inversa: "reduce mucho la distancia con el paciente -al penetrar en su interior- y la incrementa solo un poco en virtud del cuidado con que su mano se mueve entre los órganos”. En otras palabras, el cirujano renuncia a su autoridad para, en el instante decisivo, introducirse “operativamente en él” (Benjamin, 2003, p.80).

Ahora bien, esta inmersión de la mujer en la revista está recubierta de intrascendencia (a diferencia del mago cuyo acicate es la sacralidad de sus actos), operando una lectura distraída y a la vez analítica:

Distraída, en el momento en que ningún evento centra su atención en la escena y, por tanto, todo le llama la atención; profundamente analítica, en cuanto esa distensión temporal le permite jugar en esos intersticios donde las experiencias, incluso las imaginadas, se solapan y colisionan, obteniendo una "imagen rápida de la verdad”. (Romero Tenorio, Díaz Téllez y Buitrago Echeverry, 2019, p.70) 
En esta dialéctica, Bejamin halla una forma de verdad que no cala en la consciencia $\mathrm{y}$, por tanto, no se puede ejercer para el dominio. Es inútil y en esta inutilidad radica su eficacia. Se burla de los discursos totalizantes a base de situar en un mismo plano fragmentos que, en sus contextos, son altamente significantes, pero en ese nuevo escenario, por sí solos, carecen de significado. Un consejo de cómo adelgazar, y el horóscopo en una misma página. Todo recobra sentido no desde su totalidad, sino desde los oropeles que una vez fueron brillantes. Los mitos se danzan hasta el fondo hasta que pierden eficacia. Como decía Antonin Artaud, el cuerpo deja de ser penetrado en la propia penetración y es solo en ese estado de crueldad que recupera su eficacia política.

Otra dimensión importante que se le niega a la mujer es el hedonismo. Tratar de ver tras la fotografía performativa (Figura 1) un acto de reivindicación nos desvía de lo que, según los testimonios, fueron las causas por las que se disfrazaron de hombre: porque les dio la gana, por puro placer. Las propias feministas niegan esa arista del ser femenino de estas mujeres, que constituye una forma de poder. En el contexto del Cantar Maggio o Canto del Maggio (Romero Tenorio 2014, p.147), que es una tradición toscana que anuncia la primavera y consiste en que un grupo de personas ofrecen cánticos a cambio de frutas o vino, formaron una cuadrilla para ir casa por casa para recibir dones. Se trata, por tanto, simplemente de una performatividad hedonista.

\subsection{El cadáver vivo}

La fotografía que abarca el arco temporal de esta investigación tuvo vínculos con la muerte. Así lo demuestra De la Cruz (2013) en su interesante estudio sobre la fotografía post-mortem. La costumbre de captar los cadáveres como si estuvieran vivos, según la autora, responde a varias razones, que van desde un soporte para recordar (p.41) hasta una contraposición:

a la horizontalidad, impuesta por la figura del difunto, se veía enfrentada a la verticalidad como sucede con cada etapa del rito funerario, a un enfrentamiento claro de tipo visual entre vida y muerte (de pie/ tumbado). (p.111)

¿Y si los flujos simbólicos transcurrieran a la inversa? Es decir, que los vivos fuesen representados como si estuviesen muertos (Figura 2), y no como en la fotografía analizada por la historiadora del arte, donde los muertos pasan por vivos.

En el enjambre de pulsiones zumban contracciones de cuerpos en un inquietante estado de liminalidad en el que los trasvases simbólicos se desbordan de sus naturales cauces temporales. Para la señora Giovannacci, su marido ya está muerto.

Se representa un deceso probable. Esta foto estuvo tomada en la vigilia de la partida del militar a la Primera Guerra Mundial. Su posición firme, con los brazos hacia atrás, sacando pecho testimonia de su 
convicción. La esposa está sentada según los cánones de la época, en tres cuartos. Romero Tenorio (2014) demostró que esta perspectiva señala quién lleva el peso de la familia, como se puede ver en la siguiente figura (3), que al igual que en la anterior, la mujer no mira ni siquiera a la cámara.

En la Figura 2 la señora da completamente la espalda a su marido, como si ya estuviese muerto. El ambiente funesto y oscuro del cliché crea una atmósfera irrespirable. Tanto la mamá como la hija, que se toman la mano para afrontar el destino, son conscientes de que ya están solas. Los atrezos contribuyen a cargar a la fotografía de una temporalidad que desborda el presente (Geffroy, 1990). Como demostró Romero Tenorio (2014), los dispositivos escénicos, en este caso el bolso de señorita, la flor en el cabello y el gorro de militar con los que está vestida la niña, son proyecciones de un futuro deseado (p.146). En este caso, la niña lleva en su cuerpo su destino: ser una señorita (el bolso y la flor) y una huérfana (el gorro de militar) (Romero Tenorio, 2014, p.147). La señora Giovannacci configuró un dispositivo simbólico (Romero Tenorio, Riccardi y Buitrago Echeverry, 2019) de una complejidad inusual, un ritual funerario en el que a un cadáver vivo se le evita que se desintegre más allá de las capas cobrizas con el que el tiempo matiza el papel.
Figura 2. Él ya está muerto

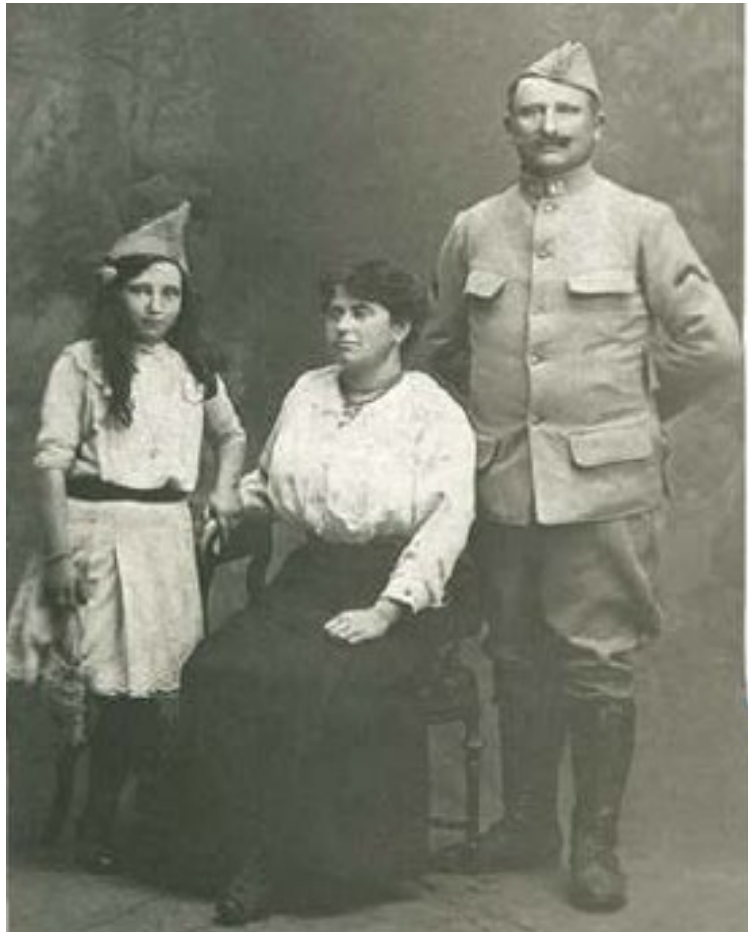

Fuente: 1916, archivo de la investigación.

Figura 3. No disparar al pianista

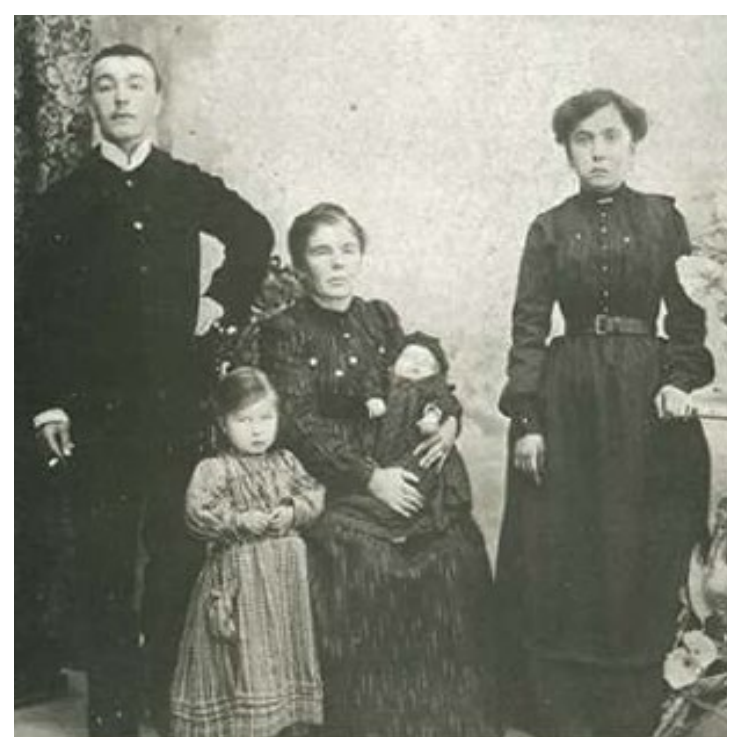

Fuente: 1914, archivo de la investigación. 


\section{LA ARTIMAÑA DE PENÉLOPE (DESDE UNA PERSPECTIVA TRASNACIONAL)}

En el contexto de la migración que se produjo en la Lunigiana a principios del siglo $\mathrm{XX}$, la fotografía de familia fungió de escenario simbólico en el que los actores que emigran configuran y negocian sus identidades con lo que permanecieron en Italia. Romero Tenorio (2014) reconoció dos tipos de fotografías de migración que corresponden a dos etapas. Las primeras son "fotografías de locación”, y "tienen la función social de transmitir a la familia una imagen del emigrante en su nuevo entorno, redefiniendo así el arco de las relaciones familiares (p.153):

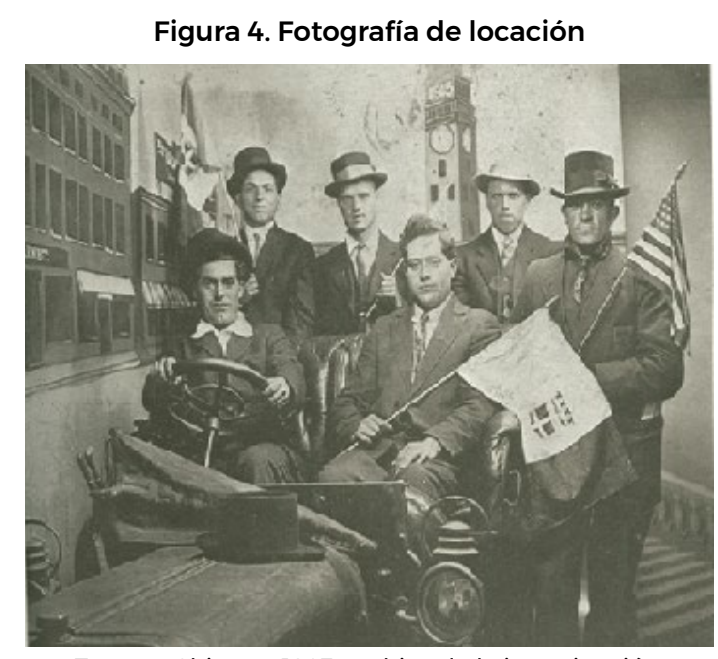

Fuente: Chicago, 1923, archivo de la investigación.

Este cliché, preñado de estereotipos del país norteamericano, servía a la familia que se quedaba en Italia para contextualizarlos. Una segunda fase corresponde a unas fotografías que muestran el estatus adquirido, y suelen ostentar a las personas en su lugar de trabajo o con el negocio:
Figura 5. Mostrar el estatus

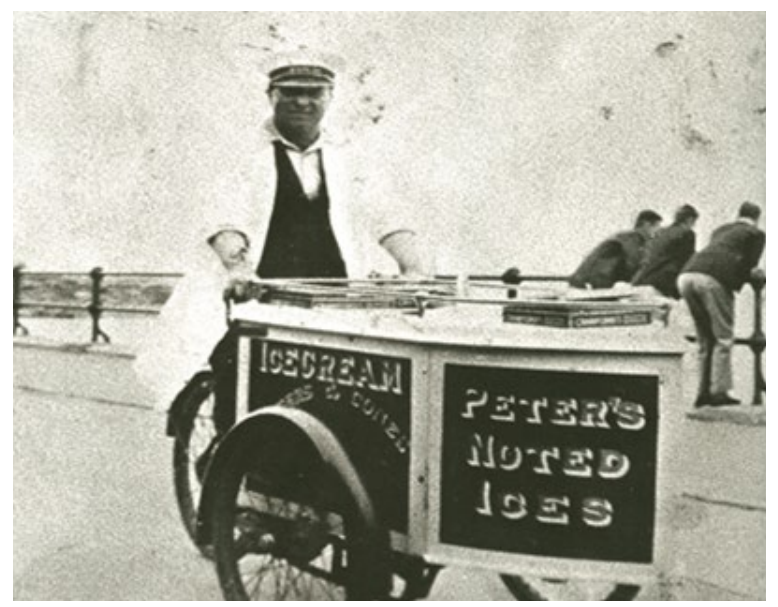

Fuente: Estados Unidos, 1929, archivo de la investigación.

A parte de estos modelos generales, se nos presentaron singulares personajes que tramaban su propio universo de pasiones y miedos en singulares mantos-fotografías. Nos referimos a Matilde, que urdió, al igual que Penélope, la siguiente artimaña, reflejada en la Figura 6.

¿Qué llevó a Matilde a montar esta imagen en un "arcaico Photoshop" (Romero Tenorio, 2014, p.152)? Ella superpuso dos fotografías, como se puede observar en la diferencia de baldosas. Anna, la hija del pequeño Roberto, el niño asustado de la foto, nunca se percató de tal estratagema; incluso el etnógrafo evitó revelar esta circunstancia a Anna, que falleció en 2008, por respeto a su antepasada. ¿Lo sabía Roberto, el marido que partió hacia Argentina? Probablemente no, ya que ni siquiera los sucesores tenían conocimiento alguno y esta foto se había integrado en el archivo de la familia con absoluta normalidad. A pesar de que nadie supiese que esta fotografía era un 
montaje, tenía un carácter público. Estaba situada en el salón de la casa, debido a la naturaleza del cliché. Romero Tenorio (2014) analiza las fotografías atendiendo al lugar de la casa en el que están ubicadas (entrada, salón, habitación). Las de la entrada están situadas en una mesa decorativa, en un aparador e, incluso, en un baúl, habitualmente están enmarcadas y representan las diferentes edades de la vida de los miembros de la familia. Por ejemplo, fotos del bautismo, de la comunión, del matrimonio, etc. Es una narrativa que transmite al invitado una idea general y a modo de película (las imágenes se suceden con coherencia) de la vida de la familia, de las etapas y le permite obtener una percepción general. Para la familia, ellos se ven en el tiempo, en la memoria, en la historia y permite a cada uno posicionarse, buscar referencias. Si el invitado tiene confianza, se le pasa al salón, donde es el lugar de representación de los vínculos familiares. Por ello, en este lugar las fotografías suelen ser grupales (a diferencia de la entrada, que son individuales para otorgarle ese carácter de narración temporal). Matilde hizo del cliché un símbolo público para representar a ojos de sí misma y de la sociedad, la inquebrantable unidad familiar. Si hubiese sido un acto privado, la habría colocado en su habitación, junto a fotos de familiares fallecidos y estampitas de santos. Romero Tenorio reconoce a estas fotografías un carácter "cultual" (2014, p.152), de culto, ya que se les reza confundidas con los santos. Cuando regresó Roberto de Argentina, esta foto fue guardada y sustituida por otra grupal, esta vez realizada en un estudio.

Figura 6. La artimaña de Matilde

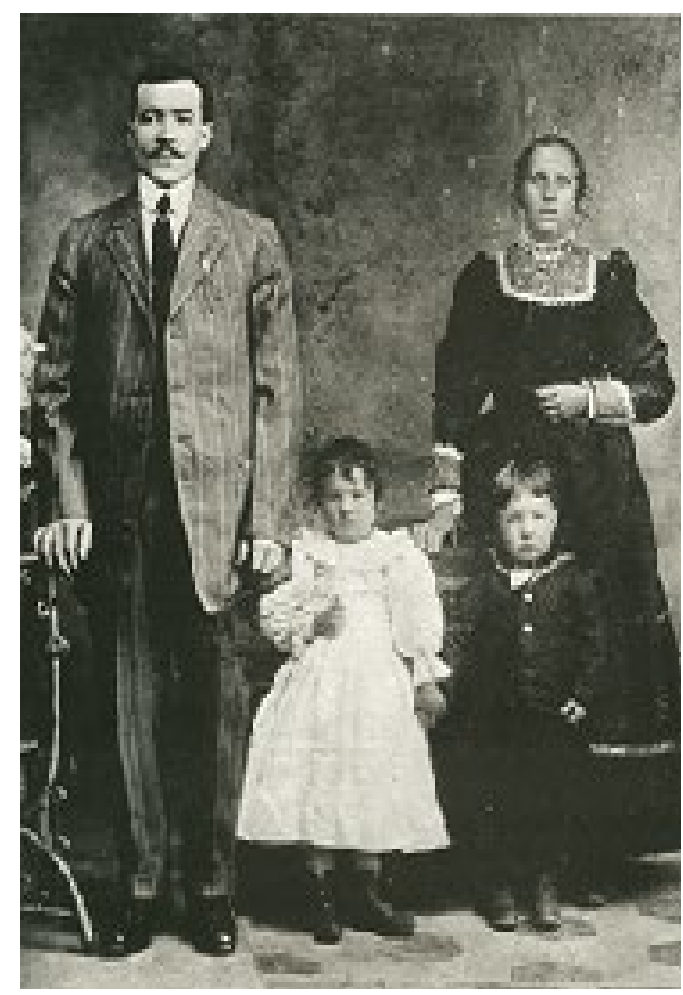

Fuente: La familia Fenocchi, alrededor de 1910, archivo de la investigación.

\section{CONCLUSIÓN}

La fotografía de familia de final del siglo XIX y principios del XX se erigía como un escenario complejo donde se negociaban identidades transnacionales, sea por medio de patrones estereotipados prêt-àporter, sea por la trama, hilo a hilo, de mantos a medida de unos imaginarios. Las primeras fotos que se enviaban desde América redefinían los contextos y el arco de las relaciones familiares, produciendo nuevos espacios de pertenencia. 
Nuestra idea de que la vida de la mujer, en aquel tiempo, fue de completa sumisión se deshilacha cuando nos encontramos con representaciones de una complejidad fascinante en la que su poder, más entallado y a medida, se ejercía en los sistemas de metaforización. Las chicas que se vestían de hombres no definían sus identidades, sino jugaban con ellas por el puro placer, algo que incluso hoy se les niega a ellas. La señora Giovannacci necesitó matar a su marido para el equilibrio de su familia; y, sí, lo hizo, aunque en una escenificación con un valor etnográfico imponderable. Y Matilde, que en el silencio urdió una artimaña similar a la de Penélope en La Odisea: un manto que de lo más profundo de su subjetividad lo hilaba y lo deshilaba para mantener, con vida, los vínculos familiares.

\section{REFERENCIAS BIBLIOGRÁFICAS}

Accolla, P. y Geffroy, Y. (1981). L'empreinte des jours. Nice: Serre

Benjamin, W. (2005). Libro de los pasajes. Madrid: Akal.

Benjamin, W. (2003). La obra de arte en la época de su reproductividad técnica. México: Ítaca.

Binazzi, A. (2019). Género y migraciones forzosas en Centroamérica y el Caribe. Una mirada antropológica para los derechos humanos de las niñas, adolescentes y de las mujeres. Collectivus, Revista de Ciencias Sociales, 6(1), 155-175. DOI: http:// dx.doi.org/10.15648/Coll.1.2019.9.

Bossio Blanco, V. (2019). "iMe caso y me voy!": migraciones transnacionales fe- meninas desde el Caribe hispánico hacia Italia. Collectivus, Revista de Ciencias Sociales 6(1), 135-153. DOI: http://dx. doi.org/10.15648/Coll.1.2019.8.

Bourdieu, P. (1979). La distinction. Critique social du jugement. París: Éditions de Minuit.

Campani, G. (2019). La migración europea y la crisis de los refugiados: un proceso complejo y multifacético. Collectivus, Revista de Ciencias Sociales, 6(1), 1533. DOI: http://dx.doi.org/10.15648/ Coll.1.2019.02.

De la Cruz Licher, V. (2013). El retrato y la muerte. Madrid: Temporae.

Díez Jiménez, A. (2015). Migración internacional colombiana: una aproximación a las intenciones y expectativas espacio-temporales de los colombianos en Sevilla. Mnemosine 6(4), 77, [en línea] http://media.wix. com/ugd/101348_453accf2oe-84bec92e7e226d4b3fc1d.pdf.

Díez Jiménez, A. (2010). Análisis de la inmigración colombiana en España, desde Sevilla (1995-2004). Háblame Ediciones. Tutorial Formación, S.L. Almería (España). ISBN: 978-84-9962-191-3.

Díez Jiménez, A. y Cabrera Izquierdo, L. (2010). Mediación intercultural, convivencia y diversidad. Háblame Ediciones. Tutorial Formación, S.L. Almería (España). ISBN: 978-84-9962-272-9.

Díaz Jiménez, R. M., De la Fuente Robles, Y. M. y Muñoz Moreno, R. (2019). Migraciones y diversidad funcional. La realidad invisible de las mujeres. Collectivus, Revista de Ciencias Sociales, 6(1), 6180. DOI: http://dx.doi.org/10.15648/ Coll.1.2019.5. 
Fouskas, T., Gikopoulou, P., Ioannidi, E., y Koulierakis, G. (2019). Gender, transnational female migration and domestic work in greece: an intersectional review of research on female migrants' Access to labour, healthcare and community associations. Collectivus, Revista de Ciencias Sociales 6(1): 101-133. DOI: http://dx. doi.org/10.15648/Coll.1.2019.7.

Gardner, K., y Grillo, R. (2002). Transnational households and ritual: an overview. Global Networks, 2(3), 179-190.

Garfinkel, H. (1968). Studies in ethnomethodology. New Jersey: Prentice Hall.

Geertz, C. (2003). La interpretación de las culturas. Barcelona: Gedisa.

Geffroy, Y. (1990). Family Fotographs: A Visual Heritage. Visual Anthropology, 3, 367-410.

Marcus, G. E. (2001). Etnografía en/del sistema mundo. El surgimiento de la etnografía multilocal. Alteridades, 11(22), 111-127.

Marcus, G. E. (1998). Ethnography through Thick and Thin. Princeton: Princeton University Press.

Monreal, M., Cárdenas, R., y Martínez, B. (2019). Estereotipos, roles de género y cadena de cuidados. Transformaciones en el proceso migratorio de las mujeres. Collectivus, Revista de Ciencias Sociales, 6(1), 83-99. DOI: http://dx.doi. org/10.15648/Coll.1.2019.06.

Radway, J. A. (1988). Reception study: Ethnography and the problems of dispersed audiences and nomadic subjects. Cultural Studies, 2(3), 359-376.

Radway, J. A (1984). Reading the romance. Women, Patriarchy, and Popular Literature. Chapel Hill: University of North Carolina Press.
Riccardi, D. y Agudelo Taborda, J. (2015). Il camino della Colombia verso la pace. Processi di pace e dignità umana, 1(1), 1-34.

Romero Tenorio, J. M., Díaz Téllez A. S. y Buitrago Echeverry, C. (2019). Béla Tarr y el cine que no cesa. Una estética visual desde lo temporal. Revista Kepes, 16(20), 41-73. DOI: 10.17151/kepes.2019.17.20.4 Romero Tenorio, J. M., Riccardi, D. y Buitrago Echeverry, C. (2019). Entramado discursivo de los troles de Podemos en las redes sociales. Estudios Sobre el Mensaje Periodístico, 25(2), 1055-1070. DOI: https://doi.org/10.5209/esmp.64825

Romero Tenorio, J. M, Cabrera Izquierdo, L. y Díez Jiménez, A. (2019). Estudio etnográfico sobre la dramatización de la alegría por clases sociales y del estigma en los adultos de la tercera edad del Asilo San Antonio (Colombia). Cultura de los Cuidados 55.

Romero Tenorio, J. M. (2017). Instante y momento oportuno en los Grafos Existenciales de Charles S. Peirce. Por una dimensión Kairológica de la Creatividad. Pensamiento, 73(276), 301-318. DOI: https://doi.org/10.14422/pen.v73.i276. y2017.004

Romero Tenorio, J. M., Buitrago Echeverry, C. y Echeverry Blanco, M. R. (2017). ¿Deslizarse o sumergirse en la interfaz? El periodismo drone y la maquetación ergonómica del espacio”. Estudios Sobre el Mensaje Periodístico, 23(1), 257272. DOI: http://dx.doi.org/10.5209/ ESMP.55595

Romero Tenorio, J. M., Zuluaga Morales, J. M. y García Hernández, A. R. (2016). La pantalla blanqueada. Maquillaje de la 
piel social en los informativos de RCN. Taborda, J. A. y Riccardi, D. (2019). La cooTextos y Sentidos, 13, 111-131. peración internacional para la paz en CoRomero Tenorio, J. M. y Díaz Téllez, A. S. (2014). Cultural Studies y Estudios de Audiencia. La Revolución Cultural de la Escuela de Birmingham en la comunicación mediática. Saarbrücken (Alemania): EAE, ISBN: 978-3-659-00268-7

Romero Tenorio, J. M. (2014). Tensiones sociales en la representación fotográfica del periodo 1870-1930. Revista Española de Investigaciones Sociológicas, 148, 135156. DOI: http://dx.doi.org/10.5477/ cis/reis.148.135

Romero Tenorio, J. M. (2014). Escritura de una aporía. Tránsitos y obstrucciones en los grafos existenciales de Charles S. Peirce. Pensamiento, $70(262)$, 177-1. DOI: https://doi.org/10.14422/pen.v70. i262.y2014.009

Salih, R. (2002). Reformulating Tradition and Modernity: Moroccan Migrant Women and the Transnational Division of Ritual Space. Global Networks, 2(3). DOI: https://doi.org/10.1111/1471-0374. 00038. lombia: los casos de Estados Unidos y de la Unión Europea (1998-2016). Geopolítica(s), 10(1), 107-134. DOI: http://dx. doi.org/10.5209/GEOP.61477

Vega Casanova, J. (2016). Presentación. Legado y vigencia del pensamiento sociológico de un sentipensante. En Alfredo Correa de Andreis. Sociología desde el Caribe colombiano. Mirada de un sentipensante, compilado por Jair Vega Casanova, $X V-X X V I I$. Barranquilla: Editorial Universidad del Norte.

\section{PARA CITAR ESTE ARTíCULO}

Buitrago Echeverry, C., Acevedo Franco, L. M., Guzmán Mera, S. S., y Ortíz Ríos, P. (2019). La artimaña de Penélope. Una mirada de género y transnacional a la migración italiana de finales del siglo XIX y principios del XX a través de la fotografía de familia. CoIlectivus, Revista de Ciencias Sociales, 6(2), 1991-213.

DOI: http//dx.doi.org/10.15648/Coll.2.2019.13

Recibido: 15/12/2018 Aprobado: 18/03/2019

Salvatori, S. y Terrón Caro, T. (2019). L'approccio intersezionale e quello transnazionale nello studio dei flussi migratori: elementi per una proposta analitica. Collectivus, Revista de Ciencias Sociales, 6(1): 35-46. DOI: http://dx.doi. org/10.15648/Coll.1.2019.3.

Solé Arrarás, A. (2017). Seguir a los difuntos. Una etnografía multisituada de las prácticas funerarias transnacionales. Antropología Experimental (pp.97-107). Obtenido de: https://revistaselectronicas.ujaen.es/index.php/rae/article/ view/3758/3068 